\title{
Editorial
}

\section{Wound healing through the ages}

T he science of wound healing has had an exiting journey over the ages. Since the caveman, man has been tending to his wounds. Wound care evolved from magical incantations, potions, and ointments, to a systematic text of wound care and surgery from Sushruta, Hippocrates and Celsus.

Right from the days of Sushruta in Ancient India, due to frequent battles and wars, healing of wounds was a matter of concern for all including ancient Chinese, Korean, Egyptian and African healers. Sushruta Samhita has two separate chapters dealing with healing of these wounds, and describes more than 100 plants for treatment of wounds both singly and in combination. ${ }^{[1]}$ Sushruta has mentioned not only procedures and drugs to obtain a clean wound (Vrana Shodan) followed by healing (Vrana Ropan) but also medicines to help treatment of keloids. ${ }^{[2]}$

Ancient Indian Surgery was a highly skilled branch of Ayurvedic medicine and known as Shalya Tantra. Eight types of surgical procedures described as "Ashtavidha Shastrakarma" were means and methods to treat the surgical diseases at that time. He clarified that blood clots, foreign materials like stones, hair, nails, fragment of fractured bone, etc., should be removed and wound should be thoroughly cleaned before applying sutures. If these materials were not removed, the wound will proceed to Pakavastha i.e., suppuration and will increase pain over affected part.

Sushruta also defined the suturing procedure as a process of tying two ends of thread for union of wound edges with the help of needle and appropriate suturing material. Four methods of suturing techniques are described in ancient texts as seevan karma- Riju granthi - straight, interrupted type, Vellitaka - continuous type,

\begin{tabular}{|l|l|}
\hline \multicolumn{2}{|c|}{ Access this article online } \\
\hline Quick Response Code: & Website: \\
\hline & www.ijps.org \\
\cline { 2 - 2 } & DoI: \\
\hline
\end{tabular}

Tunnasevani - zigzag type or subcuticular and Gophanika - interlocking or blanket type suturing.

Plants have served as healing agents of wounds since ages and Ayurvedic texts of Sushruta, Jivika, Charaka and Vagabhatta are a testament to this fact. Several drugs of plant, mineral, and animal origin are described in the Ayurveda for their wound-healing properties under the term Vranaropaka. Some of these plants have been screened scientifically for the evaluation of their woundhealing activity in different pharmacological models and patients, but the potential of most remains unexplored. In a few cases, active chemical constituents were identified. Some Ayurvedic medicinal plants, namely, Ficus bengalensis, Cynodon dactylon, Symplocos racemosa, Rubia cordifolia, Pterocarpus santalinus, Ficus racemosa, Glycyrrhiza glabra, Berberis aristata, Curcuma longa, Centella asiatica, Euphorbia nerifolia, and Aloe vera, were found to be effective in experimental models and have long been incorporated in modern medicine. ${ }^{[3]}$

Traditional Chinese Medicine (TCM) has been practiced for thousands of years and has deeply emphasized an artistic and holistic approach to healing. The concept of Yin and Yang, which describes two opposing and, at the same time, complementary aspects of any one phenomenon, is applied in the TCM approach to healing. The Yin tends to be associated with poor circulation, stagnation and poor healing, whereas the Yang tends to be associated with being overheated or having an excess of scar tissues. The ideal balance is for Yin and Yang to be in relative harmony. Acupuncture, Medical Qi Gong, which is an acupuncture technique without needles, herbal medicines, breathing exercises, massage and Feng Shui, which is an art of living in harmony with nature, all together help wounds to heal. ${ }^{[4]}$ The Chinese philosophy of the five elements, which is the basis of the universe according to Chinese Taoism, are viewed as being essential in promoting wound healing in a complementary way. The lungs have to be healthy and strong. The kidneys are considered the "mother" of the lungs and the spleen is responsible for the immune

Indian Journal of Plastic Surgery May-August 2012 Vol 45 Issue 2 
system. None of this is irrelevant even today as only a healthy body is capable of healing its wounds, no matter where they are. TCM emphasizes that the body, mind and spirit have to be stabilized and well aligned so healing can take place and promoting well being and disease prevention is of paramount importance.

Africa remains a wonderland with over 50 countries, more than 3000 languages and a myriad of cultural practices, traditional beliefs and strongly held values. A number of cultural practices and beliefs, most of which significantly affected the patients' wound care are still practiced like use of smoke, hot metal burns, dung and animal and plant products. The traditional remedies such as animal fur, saliva, soil and local herbs are often preferred over the western medicines because of both easy availability and inexpensive nature. The aetiology of wounds and practices, such as female genital mutilation, traditional circumcision and scarification, often still remain a direct cause of these wounds. ${ }^{[5]}$

The Egyptians were masters in applying and arranging bandages, and they recognized the cardinal signs of infection and inflammation. Egyptian drug therapy can be regarded as having evolved from a system rooted in magic and empirical observation. Pressure sores have been found on 5,000 year old mummies in Egypt. The ancient Egyptians used honey as a wound treatment. The 1650 B.C. Edwin Smith Surgical Papyrus, a copy of a much older document, describes at least 48 different types of wounds. A later document (Ebers Papyrus, 1550 B.C.) relates the use of concoctions containing honey (antibacterial properties), lint (absorbent properties), and grease (barrier) for treating wounds. These same properties are still considered essential in contemporary daily wound management" ${ }^{\prime[6]}$ Yet another very early account of wound healing dating back to about 2000 B.C. suggests that the Sumerians employed two modes of treatment: a spiritual method consisting of incantations and a physical method of applying poultice-like materials to the wound.

Hippocrates, a Greek physician and surgeon, 460-377 BC, known as the father of medicine, used vinegar to irrigate open wounds and wrapped dressings around wounds to prevent further injury. He washed ulcers with wine and after having softened them by oil, he dressed them with fig leaves. Galen, a notable Roman surgeon, was first to recognize that pus from wounds inflicted by the gladiators preceded wound healing.

Indian Journal of Plastic Surgery May-August 2012 Vol 45 Issue 2
Plinio used mineral remedies as lead and silver, Galen used spice ointments. These advances achieved in wound care and surgery for healing wounds by Hippocrates and Celsus were lost after the fall of the Roman Empire. In Europe, the middle ages were a regression of wound care back to potions and charms. It was not until the time when large armies started using muskets and cannons, that surgical wound care emerged again.

The 19th century brought significant advances in wound treatment. Joseph Lister, a Professor of Surgery in London, recognized that antisepsis could prevent infection. Lister placed carbolic acid into open fractures to sterilize the wound and prevent sepsis. Changes were also made to sterilize the surroundings of a wounded patient. Hand washing prior to care along with sterilization of instruments as well as wearing of gowns, masks and gloves began in 1880s.

The scale of wound infections was most evident in times of war. During the American Civil War, infected wounds accounted for some 17,000 deaths. World War I brought new types of wounds from advanced weaponry and contamination from the trenches. A Belgian military surgeon, Depage, introduced wound debridement and delayed wound closure and would use microbiological assessment to determine if wound was safe for closure.

The use of antibiotics ushered in a new era in wound care. Penicillin was first used clinically in 1940. However, the use of antibiotics did not end wound infections as resistant bacteria and new surgical interventions has risen. The primary method for wound management is prevention. The use of systemic antibiotics and surgical drainage and excision of damaged tissue are primary methods of wound management in present day.

Currently used therapies for non healing wounds include intermittent pneumatic compression (IPC) for treating chronic venous ulcers, hyperbaric oxygen therapy to address the hypoxic state of a non healing wound, biosurgery by use of sterile maggots which digest slough and necrotic tissue from the woiund and assist in debridement, laser therapy, hydrotherapy, electrotherapy, psoralen-combined with ultraviolet A therapy, radiant heat dressings, infrared therapy, and ultrasound therapy. Negative pressure wound therapy has also given a new dimension to wound care by providing a moist wound atmosphere, managing exudates, removing extracellular fluid from the wound and thus reducing oedema, 
promoting wound contraction and reversing the flow in the lymphatics, towards the suction and away from the systemic circulation.

Recent advances in nanotechnology, molecular biology and functional genomics, coupled with an increased understanding of the pathophysiology of a chronic wound have resulted in the development of novel therapies such as tissue-engineered substitutes and growth factors. Cryopreserved cadaver skin treated chemically to remove the antigenic cellular components has been used alone or in combination with cultured epidermal autografts to treat surgical wounds. ${ }^{[7]}$

Use of growth factors produced by recombinant DNA technology increase the wounds healing capacity by causing the cells to grow and attract new cells to the wound. Targeting individual phases of wound healing, growth factors can assist in all stages thus VEGF stimulates angiogenesis in granulating tissue and promote collaterals, PDGF is mitogenic for smooth muscle cells, endothelial cells and fibroblast and acts as a chemoattractants for neotrophils and fibroblasts, TGF a stimulates epithelial cells and fibroblast proliferation and TGF- $\beta$ stimulates angiogenesis and collagen metabolism. ${ }^{[8]}$

Gene therapy is another new avenue which is being explored to treat nonhealing wounds. Genes can be delivered into the wound by different methods - biological (viral vectors), physical (micro-injections) and chemical (cationic liposomes). Genes once incorporated in the healing cells affect the cells and their environment by their products of expression. Gene-activated matrix therapy involves embedding gene into a matrix which stays longer in a wound thus increasing the duration of exposure of target cells to the gene. ${ }^{[9]}$ Developments in the realm of stem cell, growth factors and gene therapy have given us a whole new horizon to explore for modulating nonhealing wounds and the caveman's wound healing journey still continues!

\section{Surajit Bhattacharya \\ Editor, IJPS \\ E-mail: surajitbh@yahoo.co.in}

\section{REFERENCES}

1. Idris M, Singh B, Singh G. The use of Medicinal plants in wound healing Lucknow: Proc. Natl. Sem Use of Traditional Medicinal Plasnts in Skin Care, CIMAP; 1994. p. 37-41.

2. Deshpande PJ, Pathak SN, Gode JD. Wound healing under the influence of certain indigenous drugs. In: Udupa $\mathrm{KN}$, Chaturvedi GN, Tripathi SN, (Editor). Advances in Research in Indian Medicine, Varanasi: B.H.U.; 1970. p. 269-303.

3. Biswas TK, Mukherjee B. Plant medicines of Indian Origin for wound healing - A Review. Int J Low Extrem Wounds 2003;2:25-39.

4. Steven $\mathrm{KH}$, Aung MD. Wound Healing with Traditional Chinese Medicine - Health Action Magazine Fall 2008 - Available from: http://www.hans.org/magazine/458/Wound-Healing-withTraditional-Chinese.html [Last accessed 30-08-2012]

5. Francis Ojok, Bua Emmanuel and Regina Akise: The impact of traditional treatment on wound care in sub-Saharan Africa: Wound International - Marcn 3, Vol. 1 available from: http://www. woundsinternational.com/editorials-and-reports/the-impact-oftraditional-treatments-on-wound-care-in-sub-saharan-africa [Last accessed 30-08-2012]

6. Available from: http://en.wikipedia.org/wiki/History_of_wound_ care [Last accessed 30-08-2012]

7. Phillips TJ. New skin for old: developments in biological skin substitutes. Arch Dermatol 1998;134:344-9.

8. Barrientos S, Stojadinivic O, Golinko MS, Bremh H, TomicCanic M. Growth factors and cytokines in wound healing. Wound Repiar Regen 2008;16:585-601.

9. Wai Ping Linda Fan, Rashid M, Enoch S. Current Advances in modern wound healing. Wounds U.K, 2010;6:22-36.

How to cite this article: Bhattacharya S. Wound healing through the ages. Indian J Plast Surg 2012;45:177-9. 